\title{
ARCH Project and the Global Initiatives of Disaster Health Management
}

\author{
Alisa Yanasan, MD; ${ }^{1,9}$ Natthanicha Pongpamon, RN, BNS; ${ }^{2,9}$ Ratrawee Pattanarattanamole, MD; \\ Rapeeporn Rojsaengroeng, MD; ${ }^{4,9}$ Tomoaki Natsukawa, MD, PhD; ${ }^{5,6,10}$ Tsukasa Katsube, MA; ${ }^{11,12}$ \\ Tatsuhiko Kubo, MD, PhD; ${ }^{7,10}$ (1) Yoshiki Toyokuni, PhD; ${ }^{8,10}$ Shuichi Ikeda, MSc ${ }^{11,12}$ (1)
}

1. Division of Public Health Emergency Management, Office of the Permanent Secretary, Ministry of Public Health, Thailand

2. Mobile Care Team, Lerdsin Hospital, Thailand

3. Khonkaen Hospital, Thailand

4. Emergency Department, Faculty of Medicine, Vajira Hospital, Thailand

5. Yodogawa Christian Hospital, Japan

6. Osaka City University School of Medicine, Japan

7. Department of Public Health and Health Policy, Graduate School of Biomedical and Health Sciences, Hiroshima University, Japan

8. DMAT Secretariat, Headquarters National Hospital Organization, Japan

9. Thai Task Force for ARCH Project

10. Japan Advisory Committee for $\mathrm{ARCH}$ Project

11. Japan International Cooperation Agency (JICA)

12. JICA Expert Team for Project for Strengthening the ASEAN Regional Capacity on Disaster Health Management (ARCH Project)

Correspondence:

Shuichi Ikeda, Chief Advisor, ARCH Project

Japan International Cooperation Agency (JICA)

(JICA Thailand office) 31st floor, Exchange Tower

388 Sukhumvit Road, Klongtoey Bangkok 10110, Thailand

E-mail: sikeda3620@outlook.jp

Conflicts of interest/financial support: The ARCH Project was funded by JICA as part of the Official Development Assistance by the government of Japan in collaboration with NIEM/MOPH Thailand as the counterpart agency. This publication was totally funded by JICA as a part of the ARCH Project. Shuichi Ikeda is a member JICA's expert team, and Tsukasa Katsube is an employee in the latter. Tatsuhiko Kubo is a member of the EMT MDS working group of the WHO. The authors do not have any conflict of interest to declare.

\begin{abstract}
Objective: The prime aim of Project for Strengthening the ASEAN Regional Capacity on Disaster Health Management (ARCH Project) is to strengthen the disaster health management (DHM) capacity in the context of personal level, Emergency Medical Team (EMT), and the regional collaboration. The ARCH Project was implemented with reference to international trends of DHM and seeks to contribute to the development of global standards.

Methods: The project established the Project Working Groups that consisted of representatives of ASEAN Member States (AMS) to develop standard operating procedures (SOP) for international EMT (I-EMT) coordination. Furthermore, it aimed to organize training sessions along with implementation of the regional collaboration drill (RCD) in accordance with I-EMT minimum requirements and in line with coordination standards set by the WHO.

Results: The ARCH Project developed the SOP and common platform for I-EMT coordination, organized training, and conducted RCDs with reference to the WHO's EMT initiative. Furthermore, it also contributed to the development of the EMT
\end{abstract}

Keywords: ARCH Project; Disaster Health Management; Emergency Medical Team (EMT); EMT Minimum Data Set (MDS); Health Emergency and Disaster Risk Management (Health EDRM)

\section{Abbreviations:}

AMS: ASEAN Member States

ARCH Project: Project for Strengthening the ASEAN Regional Capacity on Disaster Health Management EMT: Emergency Medical Team

EMTCC: Emergency Medical Team Coordination Cell

Health EDRM: Health Emergency and Disaster Risk Management

HEOC: Health Emergency Operation Center

I-EMT: International Emergency Medical Team

JAC: Japanese Advisory Committee

JICA: Japan International Cooperation Agency

MDS: Minimum Data Set

PWG: Project Working Group

SAG: Strategic Advisory Group

SASOP: Standard Operating Procedure for Regional Standby Arrangements and Coordination of Joint

Disaster Relief and Emergency Response Operations

SOP: Standard Operating Procedure

TTF: Thai Task Force

WHO: World Health Organization

Received: November 21, 2021

Accepted: December 4, 2021

doi:10.1017/S1049023X22000048

(C) The Author(s), 2022. Published by Cambridge University Press on behalf of World Association for Disaster and Emergency Medicine. This is an Open Access article, distributed under the terms of the Creative Commons Attribution-NonCommercial-ShareAlike licence (https://creativecommons.org/ licenses/by-nc-sa/4.0/), which permits non-commercial re-use, distribution, and reproduction in any medium, provided the same Creative Commons licence is included and the original work is properly cited. The written permission of Cambridge University Press must be obtained for commercial re-use. 
Minimum Data Set (MDS), an international standard DHM tool that underwent testing at the RCDs before the WHO endorsement and its utilization in actual disaster response.

Conclusion: In the process of strengthening ASEAN regional capacity in DHM, the project is constantly capturing international trends and also making significant contributions in the development of global systems and tools.

Yanasan A, Pongpamon N, Pattanarattanamole R, Rojsaengroeng R, Natsukawa $T$, Katsube T, Kubo T, Toyokuni Y, Ikeda S. ARCH Project and the Global Initiatives of Disaster Health Management. Prehosp Disaster Med. 2022;37(Suppl. 1):s11-s15.

\section{How the ARCH Project has Incorporated the WHO EMT Standards of Capabilities and Coordination A. Overall}

The Project for Strengthening the ASEAN Regional Capacity on Disaster Health Management (ARCH Project) aims to improve disaster health management (DHM) capacity in the context of personal level, Emergency Medical Team (EMT), and the regional collaboration. ${ }^{1,2}$ Two project working groups (PWGs) were set up to facilitate ASEAN Member States (AMS) representatives to discuss the ARCH activities and outputs. Terms of Reference (TOR) for each PWG are as follows.

The role of PWG1: The objective of PWG1 was to design and plan the regional collaboration drills (RCDs) (eg, develop scenarios and activities, evaluation procedures, and materials) and develop a draft regional standard operating procedure (SOP) along with the outline of the minimum requirements for DHM. Furthermore, organizing the pilot testing in order to evaluate and improve the draft regional SOP and ascertain the minimum requirements through RCDs. The role of PWG1 is to prepare a database of EMTs of AMS and develop a draft framework of health needs assessment (HNA) in emergency situations.

The role of PWG2: The objective of PWG2 is to design and develop a training curriculum (eg, objective, theme, methodology, trainers, etc.) and materials along with providing necessary support for conducting training.

The RCD was designed to examine the current situation of ASEAN international and national EMT capacity on DHM and test the proposed SOP and other regional collaboration tools developed by PWG1.

ARCH aims to develop rules and procedures for effective and swift deployment of I-EMTs in ASEAN. Therefore, the PWG1 decided to develop SOP for coordination of EMTs in ASEAN. However, the latter needed to be consistent with WHO classification and minimum standards for I-EMTs, in order to be implemented in sudden onset disasters, rather than developing unique operating procedure.

In addition, the SOP for coordination of EMTs in ASEAN was developed based on the domestic protocols of each AMS procedure, and it shall be integrated into the ASEAN SOP on humanitarian assistance in disaster situation known as the SOP for Regional Standby Arrangements and Coordination of Joint Disaster Relief and Emergency Response Operations (SASOP).

The first phase of the ARCH Project (July 2016 - June 2019) achieved development of the SOP to coordinate EMTs in ASEAN with standard report forms, which served as a common platform of effective and swift deployment of AMS I-EMT when a large-scale disaster occurs in the ASEAN region. Furthermore, it intended to clarify regarding the minimum requirements and qualifications for the members of EMTs. These two main outcomes were the cornerstone for further development of personal, team, and collaboration capacity of AMS I-EMTs by creating the standard training curriculum on DHM in the ARCH Project extension phase (July 2019 - December 2021).

\section{B. Incorporation into ARCH Training Programs/Drill}

The ARCH Project since its origin has aimed to ensure that the WHO EMT Standards are respected and actually practiced in the realm of emergency medicine in the ASEAN region. The ARCH Project has conducted a couple of types of training, in which the training participants could learn and deepen the knowledge, including WHO EMT standard, and utilize them in actual disaster situations. The ARCH training includes ASEAN regional training courses, Study visits in Japan, and RCDs. Especially, $\mathrm{RCD}$ is an iconic event among all the $\mathrm{ARCH}$ activities and has been serving as a platform for all the practitioners from the region to come face to face and apply their learning into practice.

1. Objectives of $R C D$ - The RCD has two primary objectives. The first is to practice and improve proficiency of all the AMS and their teams about the EMT international standard and ASEAN regional procedures. In the same manner, the RCD also serves as a testing ground in order to verify the feasibility of the methodologies. The second is to improve readiness of a host country with regard to their existing national response plan. Hosting the RCD benefits the country not only by checking whether their systems are sound but also by ensuring that all the relevant stakeholders, including national line ministries, national Red Cross or Red Crescent society, local NGOs, and all the practitioners, provide a formalized process to review their system in compliance with the WHO EMT and ASEAN standards, and revise them if necessary. The first objective is mainly focused on capacity development of international/regional responders whereas the latter is targeted for the host country.

In the early period of the first phase of the ARCH Project, emphasis was placed on the initial objective such as formatting the procedures and developing the templates. Hence, there was a great necessity to verify the procedures and templates in the field simulation exercise of the RCD. As the phase entered into the extension phase of the ARCH Project, the second objective pertaining to the benefits of RCD on host countries was more highlighted and needed steps were undertaken. More attention was paid to the strengthening of the coordination capacity of the host country for receiving I-EMTs based on the developed ASEAN procedures and templates.

2. Outline of the RCD-Since the beginning of the $\mathrm{ARCH}$ Project, RCD has been conducted four times to date in Thailand, Vietnam, Philippines, and Indonesia in 2016, 2017, 2018, and 2019, respectively. As the project grew, matured, and the number of the events accumulated, the event framework has been standardized. Currently, the framework is explained as follows:

a. Host Country and Venue-An upcoming host country of the $\mathrm{RCD}$ for a following year is decided with consent of all the AMS one year prior to the actual event. A country intending to host the event needs to submit a letter of Expression of Interest, 
and this will be subjected to a consensus making process with AMS. If decided, this is normally announced at the venue of the RCD.

Accordingly, the host country will decide the place where to hold the event in the country. This is decided mainly at the discretion of the host country with advice from the Mentor Group of $\mathrm{RCD}$. This group is responsible for supporting the host country to efficiently and effectively design the event to be appropriate for pursuing the RCD objectives. At this stage, the Mentor Group will assess the host country's plan from a perspective of participants' access to the venue and functionality of the venue.

b. Components of the RCD and Duration of the Event-The components of the RCD are predetermined based on the experience of past RCDs. The event is normally divided into two major segments. These are workshops and desk-top types of indoor activities. The rest are field simulation exercises where all the participants go outdoors and simulate a deployment cycle from arrival in the host country to returning to the home country. The workshops and desk-top learning usually include understanding the methodologies, actual practice of filling in standard templates, understanding the national response plan of the host country, knowledge exchange sessions regarding capacity, and so on.

The following is likely to be listed as the component:

Indoors: The activities include experience sharing regarding capacity development and understanding the EMT coordination methodology. Moreover, also included practice work with EMT templates and presentation about Disaster Response Mechanism in the host country.

Outdoors: The activities consist of arrival at entry point with customs, immigration, and quarantine process and licensure process with the host government. Coordination meeting with the Health Emergency Operation Center (HEOC) will be held and the Emergency Medical Teams Coordination Cell (EMTCC) will be organized. Daily reporting of team activities by the WHO EMT Minimum Data Set (MDS) and Health Needs Assessment is conducted. Medical referral process, Quality Assurance Visit, and demobilization process are carried out.

The above-mentioned components were organized with some other agenda items such as opening/closing remarks, keynote speech, introduction of participants, evaluation of the event, and so on. These events were part of a four-day package. The first two days are mainly spent for indoor activities, and the third day is full of field exercises, followed by the last day of wrap up of the whole event.

c. Organizers and Participants - In the preparation and execution process of the RCD, the host leadership is well-respected. However, since the host is not always aware about the preparation leading up to the completion of the event, therefore, it is the mentor group that organizes and supports the process. The mentor group was composed of experts from Thailand, Japan, and host countries in the past. Each country spares a couple of experts and supports the host.

The participants are from the AMS. Each country sends around five members to the event. Expected profile of these participants shall be: (a) familiar with the WHO EMT standards and ASEAN methodologies, (b) holding a position in charge of disaster medical response to be able to give feedback on the learning outcome, and (c) also well-exposed to earlier ARCHrelated events.

The participants from the host country are equally important, as the RCD is the best opportunity for those who normally serve in administration of emergency medicine in the host country to expose themselves to international and regional, well-acknowledged methodologies. Also, these are the right people to disseminate the methodologies in the domestic environment. The expected participants are from relevant ministries, Red Cross or Red Crescent Society, local NGOs, WHO office, universities, and so on.

d. Preparation Process-There is a preparation manual titled "Guidebook for Preparation of the ARCH Regional Collaboration Drill." It has been produced by the ARCH Project in order to standardize the preparation process and to ensure the quality of the event. The length of preparation requires at least 10 months, prior to the event. In the meantime, a series of meetings and actual venue visits are conducted by the host and supported by the mentor group.

3. Incorporation of the WHO EMT Standards into the RCD - In the undercurrent of the RCD preparation and execution process, there is always an adherence to incorporation of WHO EMT Standards. As mentioned above, there are several engineering challenges to ensure that the essence should be well-planned and in the design of each RCD.

Firstly, the leading countries of the ARCH Project are Thailand and Japan. Both of them have EMT classified by the WHO, which means that the overall direction of the ARCH Project including the $\mathrm{RCD}$ is based on a thorough understanding of the WHO EMT Standards. Secondly, leading persons of each RCD host country have undergone EMTCC training where the EMT coordination methodology is taught and practiced. ${ }^{3}$ The $\mathrm{ARCH}$ Project conducted an EMTCC course in the framework of ASEAN regional training and it was collaborated with $\mathrm{WHO} .{ }^{4}$ In the course, each AMS nominated two participants to be trained. This implies that each country has at least a couple of key resources who have a certain degree of understanding in EMT methodology. Thirdly, the mentor group for supporting the host country to prepare the event is an expert group on WHO EMT methodology. Most of the members in the mentor group are EMTCC trained or have similar experience. So, the event naturally aligns with the methodology.

Also, the RCD program is designed to apply the developed procedures and templates. The first two days of the RCD are normally spared for desk-top type workshops and practice of the established procedures with existing templates, such as the Team Registration Form, the EMT MDS Daily Reporting Form, and the Team Exit Report. The event normally proceeds to the field simulation, that is based on the WHO EMT methodology, such as using the reporting forms, coordination meeting protocols, and so on. WHO personnel are always welcome to observe and advise.

Moreover, the ARCH Project is always supported by ASEAN Secretariat as well as ASEAN Coordinating Centre for Humanitarian Assistance on disaster management, also known as AHA Centre. ${ }^{5}$ These serve as a custodian of the ASEAN Agreement on Disaster Management and Emergency Response (AADMER) and an advisor for regional context unique to ASEAN as well as the ASEAN Health Development 
Agenda. ${ }^{6,7}$ These key organizations have been working with the ARCH Project closely and have guided to create synergy with other relevant projects in the field. Since they have a well-established network with all the countries in the region, this results in disseminating the methodology and penetrating the understanding to all the relevant layers of emergency medicine in the region.

\section{How the ARCH Project has Contributed to Global Initiatives}

Information management is a vital issue during disaster response. However, since EMTs are dispatched from various organizations, unified command or coordination remains as the universal challenge. The slogan "One ASEAN, One Response” clearly expresses the strong intention of AMS to overcome this issue. ${ }^{8}$ Internationally, the WHO is proposing standard forms to address this challenge. ${ }^{9}$ In 2016, the WHO set up a working group to develop standard EMT daily report form. The daily report form was endorsed by the WHO EMT Strategic Advisory Group (SAG) in February 2017 as the EMT MDS Daily Report. ${ }^{10,11}$ Importantly, the ARCH Project has been testing this EMT MDS form since the start-up RCD in 2016, before the aforementioned endorsement. At that $\mathrm{RCD}$, all participating states agreed to utilize the form regionally. This positive evaluation was informed to the SAG of the WHO and thereby contributed to the international endorsement process. The ARCH Project aims to establish regional standards and mechanisms, but it also provides valuable opportunities to test and verify usefulness of global standards which are still under development.

The ARCH Project is also influencing actual operations of I-EMTs. The ARCH Project held the EMTCC Training Course with the WHO in 2019. One faculty and two participants trained at this course were dispatched to the EMTCC during Cyclone Idai response, Mozambique in 2019, and supported the EMT coordination by the Ministry of Health of Mozambique. ${ }^{12}$ The supporting members activated the EMT MDS daily report system, which enabled visualization of clinical activities of all deployed EMTs and realized the data-based unified coordination of various EMTs as if they were a single entity and making one response.

Another important outcome of the ARCH Project is to enhance the academic network on DHM in ASEAN. The International Conference on the Implementation of the Health Aspect of the Sendai Framework for Disaster Risk Reduction 2015-2030 (Sendai Framework), held on 10-11 March 2016 in Bangkok, Thailand, adopted the "Bangkok Principles" which articulates measures that could assist countries in implementing the health aspects of the Sendai Framework for Disaster Risk Reduction. ${ }^{13,14}$ The successive project of ARCH (ARCH2) will support the implementation of the Plan of Action to implement the ASEAN Leaders' Declaration on Disaster Health Management that was designed based on the "Bangkok Principles," ARCH2 could directly contribute to realize the "Bangkok Principles" in the ASEAN region. ${ }^{15,16}$

It is critical to enhance academic activities in DHM in ASEAN according to the regional context of multiple hazards, vulnerabilities, and coping capacities. With response to the Sendai Framework, WHO has developed Health Emergency and Disaster Risk Management (Health EDRM) Framework and established the "WHO Thematic Platform for Health EDRM Research Network" (Health EDRM RN) to promote and strengthen research and knowledge synthesis, which contributes to the implementation of those frameworks. ${ }^{17,18}$ Therefore, enhancement of academic network in ASEAN should have close collaboration with the WHO Health EDRM RN.

\section{Conclusion}

The ARCH Project has organized trainings in DHM in line with the WHO EMT Initiative, and has developed the SOP for I-EMT coordination according to the WHO standards, which is in the process of integration into the SASOP, and has organized the RCDs as opportunities to test the SOP and its regional tools. In order to enhance the coordination of EMTs, the ARCH Project co-hosted the EMTCC training course with the WHO, and has contributed to the development of the EMT MDS via testing at the RCDs before the WHO's endorsement, the later became the global DHM tool utilized in actual disaster response. In the process of strengthening ASEAN regional coordination and collaboration mechanisms in DHM, the project is constantly capturing international trends surrounding DHM, as well as seeking to make contributions to the development of global systems and tools. Academic enhancement in ASEAN will have a significant impact and contribution in the global research network on DHM.

\section{Author Contribution}

This manuscript was conceptualized and contributed by following authors: Alisa Yanasan, Tomoaki Natsukawa, and Tsukasa Katsube (Incorporation of international standards to $\mathrm{ARCH}$ Project), Tatsuhiko Kubo (Reflecting ARCH testing results to international initiative). All authors have read the final manuscript and agreed for publication.

\footnotetext{
References

1. ASEAN. Joint statement of the 6th ASEAN Plus Three Health Ministers Meeting. https://aseanplusthree.asean.org/wp-content/uploads/2020/01/6th-ASEAN-PlusThree-Joint-Statement_17-Sep-2014_Adopted-by-PrepSOM.pdf. Published 2014 September 6, 2021

2. JICA. The Survey on the Current Situation of Disaster/Emergency Medicine System in the ASEAN Region: Final Report. https://openjicareport.jica.go.jp/pdf/12237384. pdf. Published 2015. Accessed May 5, 2021.

3. WHO. Emergency Medical Teams Coordination Handbook 2016. Draft Version 10 (June 2016). https://www.irsp-caq.org/pluginfile.php/174/mod_glossary/attachment/ 177/WHO\%20Emergency\%20Medical\%20Team\%20Coordination\%20Handbook.pdf. Accessed September 6, 2021.

4. WHO and ASEAN (ARCH Project) conduct Emergency Medical Team Coordination Cell Training in Bangkok, Thailand, February 2019. WHO. https://
}

www.who.int/southeastasia/news/events/detail/2019/02/17/default-calendar/whoand-asean-(arch-project)-conduct-emergency-medical-team-coordination-cell-trainingin-bangkok-thailand-feb-2019. Accessed September 6, 2021.

5. The ASEAN Coordinating Centre for Humanitarian Assistance on disaster management. https://ahacentre.org/. Accessed September 6, 2021.

6. ASEAN. The ASEAN Agreement on Disaster Management and Emergency Response (AADMER). http://agreement.asean.org/media/download/20190702042 042.pdf. Published 2010. Accessed September 6, 2021.

7. ASEAN. ASEAN Post-2015 Health Development Agenda (2016-2020). https:// asean.org. Accessed September 6, 2021.

8. ASEAN. The ASEAN Declaration on One ASEAN, One Response: ASEAN Responding to Disasters as One in the Region and outside the Region. https:// asean.org. Accessed September 6, 2021. 
9. WHO. Classification and minimum standards for emergency medical teams. https:// extranet.who.int/emt/guidelines-and-publications\#dflip-df_manual2/1/ Published 2021 Accessed September 4, 2021.

10. Benin-Goren O, Kubo T, Norton I. Emergency medical team working group for minimum data set. Prehosp Disaster Med. 2017;32(S1):S96.

11. Kubo T, Yanasan A, Herbosa T, Buddh N, Fernando F, Kayano R. Health data collection before, during, and after emergencies and disasters-the result of the Kobe Expert Meeting. Int J Environ Res Public Health. 2019; 16(5):893.

12. Mozambique: Tropical Cyclone Idai, 2019. Virtual OSOCC UN-OCHA. https:// vosocc.unocha.org/GetFile.aspx?xml=rss/6063ziO0GcibZfOBHzXrlREaKTwN3dND8O IHBIScmSjJd5gx_11.html\&tid=6063\&laid=1. Accessed September 6, 2021.

13. UN-ISDR. Sendai Framework for Disaster Risk Reduction (2015-2030). http:// www.preventionweb.net/files/43291_sendaiframeworkfordrren.pdf. Published 2015 Accessed September 6, 2021.
14. WHO. Bangkok principles to implement the health aspects of Sendai Framework for Disaster Risk Reduction (2015-2030). http://www.who.int/hac/events/2016/ Bangkok_Principles.pdf. Published 2016. Accessed September 6, 2021.

15. ASEAN. ASEAN Leaders' Declaration on Disaster Health Management. https:// asean.org/wp-content/uploads/2017/11/4.-ADOPTION_2017_ALD-on-DHM_ Endorsed-13th-AHMM.pdf. Published 2017. Accessed September 6, 2021

16. ASEAN. Plan of Action to implement the ASEAN Leaders' Declaration on Disaster Health Management (2019-2025). https://asean.org. Accessed September 6, 2021.

17. WHO. Health Emergency and Disaster Risk Management Framework. https:// www.who.int/hac/techguidance/preparedness/health-emergency-and-disaster-riskmanagement-framework-eng.pdf. Accessed September 6, 2021.

18. Kayano R, Nomura S, Abrahams J, Huda Q, Chan EYY, Murray V. Progress towards the development of research agenda and the launch of knowledge hub: the WHO thematic platform for health emergency and disaster risk management research network (Health EDRM RN). Int J Environ Res Public Health. 2021;18(9):4959. 